\title{
From drugs to deprivation: a Bayesian framework for understanding models of psychosis
}

\author{
P. R. Corlett • C. D. Frith • P. C. Fletcher
}

Received: 10 February 2009 / Accepted: 29 April 2009/Published online: 28 May 2009

(C) The Author(s) 2009. This article is published with open access at Springerlink.com

\begin{abstract}
Introduction Various experimental manipulations, usually involving drug administration, have been used to produce symptoms of psychosis in healthy volunteers. Different drugs produce both common and distinct symptoms. A challenge is to understand how apparently different manipulations can produce overlapping symptoms. We suggest that current Bayesian formulations of information processing in the brain provide a framework that maps onto neural circuitry and gives us a context within which we can relate the symptoms of psychosis to their underlying causes. This helps us to understand the similarities and differences across the common models of psychosis.

Materials and methods The Bayesian approach emphasises processing of information in terms of both prior expectan-
\end{abstract}

\section{P. R. Corlett · P. C. Fletcher}

Department of Psychiatry, Brain Mapping Unit,

University of Cambridge,

Downing Site,

Cambridge CB2 3EB, UK

C. D. Frith

Wellcome Trust Centre for Neuroimaging,

12 Queen Square,

London WC1N 3BG, UK

P. R. Corlett

Abraham Ribicoff Research Facility, Connecticut Mental

Health Centre, Yale University Medical School,

New Haven, CT, USA

\section{P. C. Fletcher $(\square)$}

Department of Psychiatry, Addenbrooke's Hospital,

University of Cambridge,

P.O. Box 255, Cambridge CB2 2QQ, UK

e-mail: pcf22@cam.ac.uk cies and current inputs. A mismatch between these leads us to update inferences about the world and to generate new predictions for the future. According to this model, what we experience shapes what we learn, and what we learn modifies how we experience things.

Discussion This simple idea gives us a powerful and flexible way of understanding the symptoms of psychosis where perception, learning and inference are deranged. We examine the predictions of the cognitive model in light of what we understand about the neuropharmacology of psychotomimetic drugs and thereby attempt to account for the common and the distinctive effects of NMDA receptor antagonists, serotonergic hallucinogens, cannabinoids and dopamine agonists.

Conclusion By acknowledging the importance of perception and perceptual aberration in mediating the positive symptoms of psychosis, the model also provides a useful setting in which to consider an under-researched model of psychosis - sensory deprivation.

Keywords Bayesian learning - Prediction error - Perception · Belief · Psychotomimetic drugs

\section{Introduction}

[The] world is ...what we make of it. Once our mould for world making is formed it most strongly resists change. The psychodelics (sic) allow us, for a little while, to divest ourselves of these acquired assumptions and to see the universe again with an innocent eye (Osmond 1957). 
In the first review of psychotomimetic drugs and their clinical implications, Humphrey Osmond outlined what he felt were the future directions for the field of model psychoses. He emphasised a number of themes, including the importance of drug-induced alterations in perceptions and expectations. This is an interesting starting point for our paper because, as has often been noted (Corlett et al. 2007; Freedman 1974; Maher 1974; McGhie and Chapman 1961), such alterations may be an important component of the state of emerging psychosis (see Corlett et al. 2007 for discussion).

Drug models of psychosis need a cognitive neuroscience perspective. Without it, though the pharmacology of such models may be understood with great subtlety and sophistication, our understanding of how the pharmacology links to the symptoms will remain incomplete (Kandel 1999; Kapur 2003). It may ultimately prove that this link will be critical in understanding how it is that such apparently different manipulations lead to common symptoms.

The cognitive framework that we apply derives from a current theory of brain function (Friston 2005a) and emphasises the hierarchical interactions between top-down and bottom-up processes, which enable our perception and prediction of the world (Friston 2005a; Mumford 1992). Our suggestion is that all experimental interventions that induce psychotic symptoms affect the interaction between subjects' predictions about the world and the sensory inputs that they encounter. Under normal circumstances, this interaction shapes experience and learning and, when it is disrupted, these will be correspondingly altered, engendering the altered experiences that characterise the effects of psychotomimetic drug administration (Freedman 1974) as well as the early stages of endogenous psychoses (Maher 1974; McGhie and Chapman 1961).

Having drawn attention to the key features of this model, we will outline how the processes might be implemented in the brain. We will go on to consider how each of the major psychotomimetic drugs interacts with this model of brain function and therefore how these apparently very different neurochemical manipulations may produce common psychological effects. There are, however, notable differences between the psychotomimetic drugs, and we will attempt to account for these within the scheme. Finally, we will test the predictions of our model with reference to sensory deprivation - a preparation that induces psychotic symptoms non-pharmacologically (Bexton et al. 1954; Scott et al. 2007).

\section{Learning, expectation and mismatch: Bayesian ideas of how we experience the world}

Bayesian perspectives on cognitive processing are now very widespread (Shanks 2006). They emphasise a central theme that has long been present even in models that do not explicitly mention Bayes: that of perception as 'unconscious inference' (Barlow 1990; Helmholtz 1871/1971). The key insight offered here is that our perception (our experience of the world) is conditional upon what we expect and in turn leads to inferences about the world, which alter future expectations. There are numerous illusions which reflect this simple truth, producing their effects by appealing to prior beliefs such that incoming sensory information is seemingly altered to fit with these. This is the essence of Bayes' Theorem: Incoming information is interpreted in light of our prior expectations.

Critical to understanding such models is the recognition that mismatches between expected and actual inputs, known as prediction errors (Rescorla and Wagner 1972; Schultz and Dickinson 2000), are important in learning and experience. Bayesian treatments of learning and perception represent subjects' beliefs-their predictions about the world-as a probability distribution (Kruschke 2008). A key problem faced by the brain is to infer the causes of sensory events in the environment (Friston 2005a) and to use those causes in cognition and comportment (Mumford 1992). A measure of its success at any time is if the environment is well-predicted, that is, if prediction error (also referred to as 'free energy'; Friston 2005a) engendered by environmental events is minimised. To meet the challenge of minimising error, new information must be integrated with existing world models, where necessary leading to updating of these models such that recurrence of that particular information can be made predictable.

In terms of David Marr's levels of analysis (Marr 1982), the model offers an explanation of what the brain must achieve: First at the computational level, it predicts its sensory inputs in order to respond adaptively to its environment. Second, at the algorithmic level, it employs a hierarchical Bayesian strategy to make and adapt this prediction. Third, at the level of implementation, we suggest that feedback (NMDA) and feed-forward (AMPA) signalling in the hierarchy are responsible for the specification of the priors (or predictions) and the prediction error respectively and that, furthermore, the impact of a particular prediction error is modulated by various slow, modulatory neurotransmitters (dopamine and acetylcholine).

The same interactive framework has been applied to single neurons, whose behaviour is driven by their inputs as well as their expectancies based on prior experience (Deneve 2008a, b; Fiorillo 2008). In one such model, the inputs are specified by glutamatergic signals incumbent upon the cell. In these finer-grained treatments, priors are specified by the number and functional status of potassium channels in the cell membrane, which modulate the cell's responsivity to stimulation (Fiorillo 2008). We note with interest that individuals with an autoimmune disorder, 
causing them to raise antibodies to their voltage-gated potassium channels, experience delusional beliefs (Hudson et al. 2008; Parthasarathi et al. 2006). In our framework, impairing potassium channel function would perturb the specification of priors at the single cell level. Furthermore, the slower, modulatory neurotransmitters like dopamine and acetylcholine, which we argue are also involved in the top-down specification of priors, interact with membrane potassium channels and may modulate sensory expectancies in this way (McCormick et al. 1993).

However, the model is hierarchical and, although this may be an efficient approach to neural coding (Friston $2005 a)$, it is vulnerable to disruption particularly through the inconsistent specification of priors. Perhaps the distortion of a sensory message through the system's hierarchy might be analogous to something resembling the children's game 'Telephone'. In this game, children sit in a circle, and one whispers a story in the ear of their neighbour, who whispers it to their neighbour and so on, until the story passes around the circle. The first and last stories never match, and the more children involved in passing the message, the greater the distortion (Lyons and Kashima 2003). At each level, any ambiguity (noise) in the message is resolved according to priors superimposed at that level-what is known changes the interpretation of the percept (Bartlett 1932; Lyons and Kashima 2003) — the consequence being a marked and increasing departure of the message from its original meaning. Such a departure might explain the perceptions and beliefs of the psychotic state (Fletcher and Frith 2008).

Some theoretical models of psychosis have drawn, both implicitly and explicitly on this framework. Acknowledging the importance of interactions between prior ('stored') beliefs and current sensory input, Gray and Hemsley (Gray et al. 1991) speculated that psychosis arises when abnormal matches and mismatches occur, making the world difficult to prioritise, learn about and understand. Such a state is characterised by perceptual changes wherein background stimuli that would normally be considered irrelevant are imbued with inappropriate significance, an experience which demands explanation (Freedman 1974; Kapur 2003; McGhie and Chapman 1961). Hemsley and Garety discussed delusions in terms of deviation from optimal Bayesian interpretation of the world (Hemsley and Garety 1986). More recently, models of psychosis drawing on advances in cognitive neuroscience have taken these ideas further (Kapur 2003) and have appealed directly to hierarchical Bayesian models (Young 2008) in interpreting delusions and hallucinations (Fletcher and Frith 2008; Friston 2005a). Here, we attempt to extend these perspectives by considering this model of processing in terms of underlying neurochemistry.

The key cognitive model here, put simply, is that our beliefs and percepts emerge from the interaction of bottom- up and top-down processes. Strong top-down effects (akin to prior beliefs) change sensory experience, leading perhaps to sensory percept in the absence of a genuine stimulus (a hallucination). Conversely, aberrant bottom-up signals strongly indicate that the current priors are wrong and that beliefs (priors) must be changed to explain the world. Such aberrant changes in beliefs may provide the germ of a delusion and will, moreover if they can account for the aberrant sensory signals, be maintained (Fleminger 1992; Fletcher and Frith 2009; Pally 2005, 2007). One key point about this model is that the distinction between psychopathology that is essentially 'sensory' in nature (hallucinations) and that which is related to belief (delusions) is an over-simplification. It would be simplistic to argue that exclusively bottom-up (Maher 1974) or solely top-down (Garety et al. 1994) explanations of psychopathology are sufficient to explain symptoms. Indeed, there are situations in which either direction of processing can be responsible for the aberrations of experience that underlie the positive symptoms of psychosis. We do suggest however that a tendency towards excessive bottom-up signalling can portend the construction of a delusional belief (especially in the context of weakened top-down priors), while a relative imbalance of processing in favour of top-down signalling (often in the face of noisy or unpredictable bottom-up inputs) can lead to hallucinations and the maintenance of delusional beliefs.

Bayesian processing in the brain: possible underlying neurocircuitry

\section{Glutamate and GABA}

To be successful, we must sustain a set of prior beliefs that are sufficiently robust that we do not react reflexively and chaotically to any incoming sensory stimulus. At the same time, these beliefs (priors) must not be so immutable that responses become fixed, stereotypical and unadaptive to change. The Bayesian hierarchical organisation introduced above may be important in striking this balance. Information progresses from regions more proximal to sensory inputs towards more distal, abstract representations in associational cortices (Mesulam 1998). Within this hierarchy, feedforward connections transfer information from the bottom upwards and feedback connections mediate the top-down specification of predictions (Friston 2005a). These connections are reciprocal but they are functionally asymmetrical; forward connections have sparse axonal bifurcations and are topographically organised, whereas backward connections are more divergent, having abundant axonal bifurcations and a more diffuse topography (Angelucci et al. 2002a, b).

Forward connections are driving and always elicit a response, whereas backward connections are modulatory 
(Buchel and Friston 1997), that is, they tune the responsiveness to other inputs (Sherman and Guillery 1998). Critically, from the perspective of this paper, in which we speculate on the consequence of neurochemical perturbation, forward connections signal via fast post-synaptic AMPA and $\mathrm{GABA}_{\mathrm{A}}$ receptors, while modulatory effects are mediated via slower NMDA receptors, suggesting a more enduring role than phasic sensory-evoked responses (Friston 2005a). Thus, in terms of this model, the 'bottom-up' information proceeds via forward AMPA signalling and the top-down predictions (the priors which determine the impact of the bottom-up signal) via NMDA receptors. If a small mismatch between expectancy and experience occurs, the top-down aspect of the system is able to cancel the prediction error; however, if the prediction error is larger, then the top-down priors (which represent the estimated world model) should be altered such that the prediction is more appropriate next time around. In this case, learning has occurred (Fig. 1).

While this hierarchical Bayesian arrangement fits well with the neurobiology of the visual system (Friston 2005a; Mumford 1992), many cortical systems adhere to similar hierarchical principles (Hilgetag et al. 2000). Importantly, the frontostriatal system that mediates reward learning has been considered similarly hierarchical (Bar-Gad and Bergman 2001; Bar-Gad et al. 2000, 2003). Indeed, the functional anatomy of this learning system (Lorincz 1997) and its behavioural output have been scrutinised within this Bayesian framework (Courville et al. 2006; Kruschke et al. 2005). Frontostriatal prediction error signals are intimately involved in causal learning and reasoning (Corlett et al. 2004; Fletcher et al. 2001; Turner et al. 2004). Recent computational neuroscience models highlight the role of prediction error in perceptual learning and decision making, both in forging associations between sensory representation and in tuning perceptual sensitivity in middle temporal cortex (Law and Gold 2009). Moreover, den Ouden and colleagues recently demonstrated powerful regulatory relationships between sensory cortex responses and frontostriatal prediction error signals when human subjects learned the relationships between visual and auditory stimuli (den Ouden et al. 2009).

The link between the proposed Bayesian framework and the traditional reward-prediction error view also receives support from neurochemical and electrophysiological analyses; the prediction error coding midbrain dopamine neurons co-release both dopamine and glutamate at their pre-frontal projections sites (Lavin et al. 2005), and the impact of future prediction error signals is under top-down regulation from pre-frontal cortex through NMDA receptor-based mechanisms (Grace 1991). These relationships support the notion that prediction error processing is a basic mode of brain function (Schultz and Dickinson 2000) and that perception, learning and prediction error are intimately linked (Barlow 1990).

\section{The role of modulatory neurotransmitters}

We have focussed on glutamatergic signalling in the visual system and its role in prediction error. Within the frontostriatal and sensory systems, other neuromodulators like dopamine, acetylcholine and serotonin may provide valuable additional information for the system. Friston suggests that this is in the form of something akin to a 'confidence estimate' on the information being conveyed between regions (Friston 2005a). Put simply, if the unit of information carried between regions or levels of the hierarchy is the prediction error (Fiorillo 2008), this will have both magnitude and uncertainty. Optimal inference requires consideration of both measures. If, as we have suggested, fast glutamate signalling codes the presence and magnitude of mismatch, slower, neuromodulators represent the uncertainty in that inference (Friston 2005a). This uncertainty signalling role has been ascribed to various neuromodulators, including dopamine (Fiorillo et al. 2003) and acetylcholine (Yu and Dayan 2002, 2005).

During reward learning, both dopaminergic and cholinergic signals are involved in coding decision uncertainty. In simple appetitive Pavlovian conditioning, during the period between cue offset and reward delivery, Fiorillo and colleagues recorded a gradually ramping dopamine signal, of greatest magnitude when the forthcoming outcome was most uncertain (i.e. when the cue that had just been presented was equally predictive of reward or no reward). Furthermore, corticopetal acetylcholine release occurs in response to prediction errors and serves to sculpt the neural representation of sensory cues associated with prediction error responses (Bao et al. 2001). This modulation of sensory processing by acetylcholine has recently been confirmed in visual cortex by Herrero and colleagues who argue that an interaction between acetylcholine and glutamatergic feedback mediates attentional processing in sensory areas. Increased levels of acetylcholine alter the strengths of the connections in primary visual cortex and the biophysical state of sensory neurons, which may then allow spatially specific glutamatergic feedback to enhance the processing of specific incoming information (Herrero et al. 2008), with a view to learning more about the previously unpredictable stimulus (Pearce and Hall 1980).

We have depicted a model of processing involving predictions and outcomes, with mismatches between the two leading to learning and thereby to changes in subsequent predictions. The model relates Bayesian ideas of inference, experience, belief and learning and also highlights principles of reciprocity, which are upheld in brain structure and function. There is also evidence for aligning such a system to particular neurochemical circuitry. It follows that deficits in the system might predict disturbances in perception, learning and inference. In the setting of this simple model, 

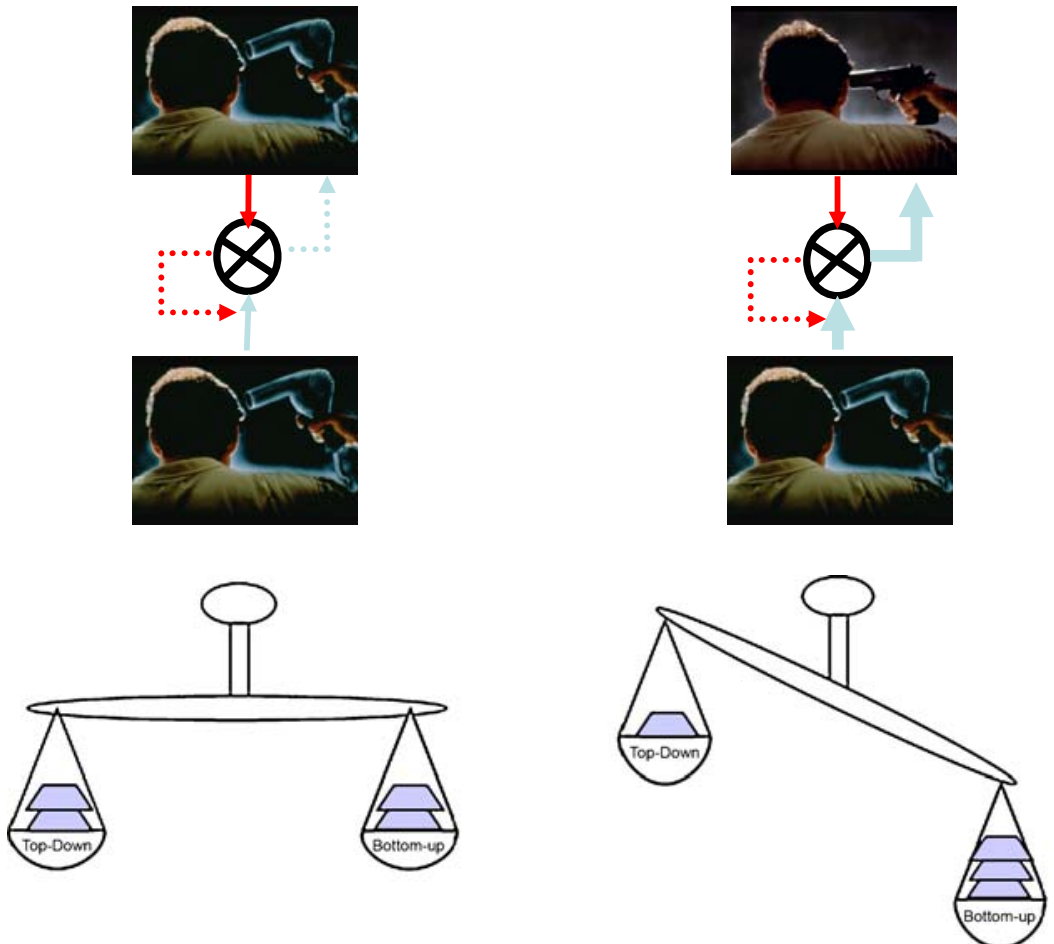
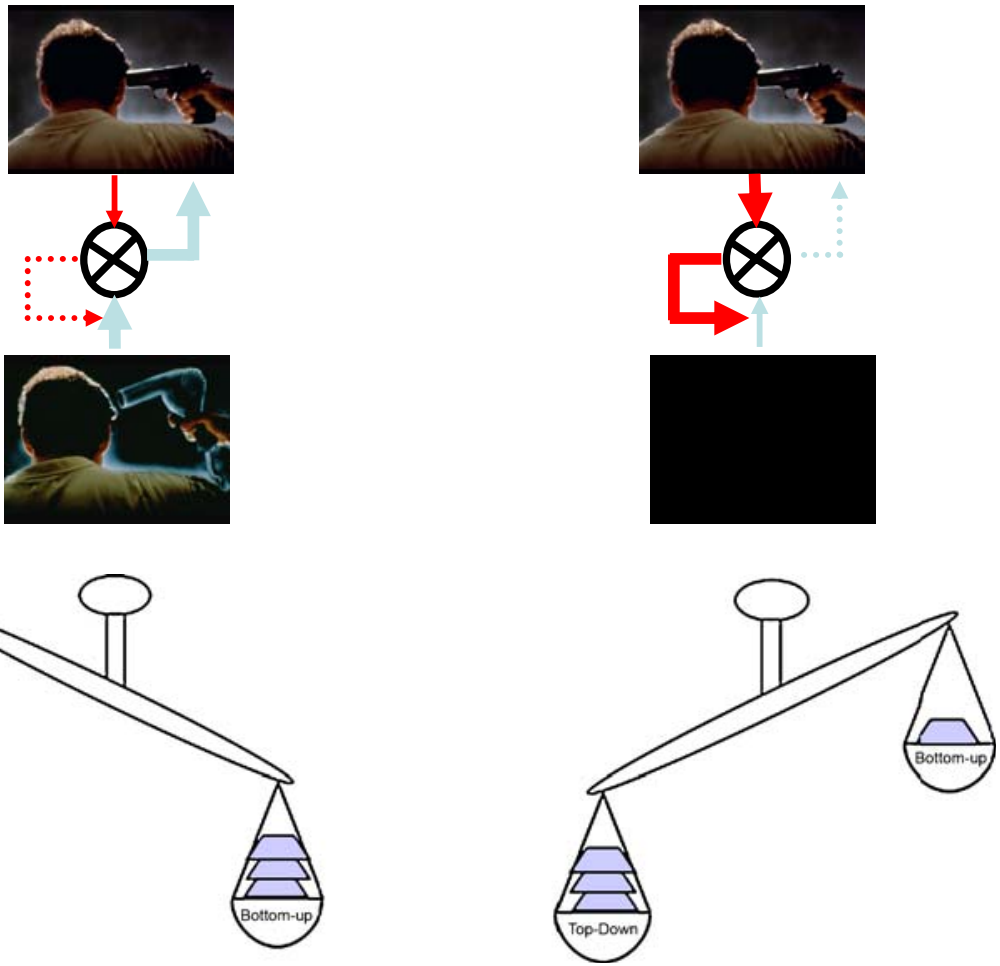

Fig. 1 A schematic representation of the effects of a shift in balance between bottom-up and top-down processing. Bottom-up signal is represented by blue arrows and top-down signal ('priors') by red arrows. Discrepancies between these signals are presented by differences in the thickness of the arrows and by the cartoon scales. Under normal circumstances (left panel), the match between bottom-up signal and prior knowledge means that there is no requirement to change prior beliefs and perception is normal. If, however, there is

we now consider the main pharmacological models of psychosis - glutamatergic, serotonergic, cannabinoid-based and dopaminergic. We outline for each the psychotic phenomena that they replicate and discuss how each model's putative neurochemistry might relate to the Bayesian model of psychopathology outlined above.

\section{Ketamine and psychotic symptoms}

Both ketamine and PCP block NMDA receptor transmission in mammalian neurons (Anis et al. 1983). This observation, coupled with the psychopathology induced by ketamine in healthy volunteers (Corlett et al. 2006; Krystal et al. 1994; Oye et al. 1992) and patients with schizophrenia (Malhotra et al. 1997), led to the development of the NMDA hypofunction model of schizophrenia (Javitt and Zukin 1991; Kornhuber 1990).

Single doses of ketamine induce a transient psychotic state in healthy volunteers characterised by perceptual aberrations, delusion-like ideas, thought disorder, blunted affect and emotional withdrawal (Bowdle et al. 1998; persistent bottom-up firing (prediction error), prior beliefs will continually fail to match the incoming signal and will need to be changed in order to accommodate the signal and minimise the persistent prediction error. This, we suggest, is a basis for changed beliefs characteristic of delusions (middle panel). If, on the other hand (right panel), strong priors exist in the absence of strong reliable bottom-up signal, these priors may be sufficient to create a percept, a basis, we suggest for hallucinations

Corlett et al. 2006; Krystal et al. 1994; Malhotra et al. 1996; Newcomer et al. 1999; Oye et al. 1992; Vollenweider et al. 1997a, b). Particularly relevant to the present model, ketamine affects the intensity and integrity of the sensory experience (Krystal et al. 1994). For both auditory and visual perception, acuity is increased and background stimuli become more salient (Krystal et al. 1994; Oye et al. 1992; Vollenweider et al. 1997a, b).

In addition to impairing NMDA transmission, ketamine binds to $D_{2}$ dopamine receptors (Kapur and Seeman 2001) and induces striatal dopamine release in healthy volunteers (Smith et al. 1998). The magnitude of this release correlates with the intensity of ketamine-induced psychosis (Breier et al. 1998; Vollenweider et al. 2000). However, haloperidol, an anti-psychotic which affords high $\mathrm{D}_{2}$ receptor blockade, fails to reverse the psychotomimetic effects of ketamine (Krystal et al. 1999). On the other hand, compounds which reduce pre-synaptic glutamate release do attenuate the psychotic symptoms (Anand et al. 2000) as does blockade of AMPA receptor function in experimental animals (Moghaddam et al. 1997). 
It appears therefore that these drugs, while blocking NMDA transmission, may actually potentiate post-synaptic AMPA currents (Shi and Zhang 2003). MK801, a congener of ketamine and PCP, decreases burst activity but increases the number of randomly distributed single spikes in prefrontal neurons of awake rats (Jackson et al. 2004). Jackson and colleagues postulate that the increased random spiking is induced by AMPA receptor stimulation and that decreased burst firing is induced by NMDA receptor blockade (Jackson et al. 2004). The reduction in burst firing may cause a reduction in signal transmission efficiency of pre-frontal cortex neurons (Miller and Cohen 2001; O'Donnell and Grace 1995), impairing the cortical mediation of normal behaviours. At the same time, random spikes may increase cortical noise, thus impairing the filtering of irrelevant information and promoting the transmission of misinformation (Lisman and Grace 2005).

In the context of the current model, we relate the random spiking mediated by AMPA receptor stimulation to inappropriate feed-forward information (i.e. prediction error), while the decreased burst firing would represent the impaired specification of prior expectancies. In short, we suggest that AMPA upregulation leads to a disturbance within the model that repeatedly engenders, through aberrant, bottom-up, prediction error, a sense that incidental stimuli or events are associated with a prediction error and are therefore special or 'salient', requiring attention and explanation (Fig. 2b). The world begins to feel different, leading to erroneous explanations and even ideas of reference (Pomarol-Clotet et al. 2006). In support of this, our own data suggest that subjects who experience the most profound perceptual changes experienced under ketamine are more likely to develop transient delusion-like beliefs (Corlett et al. 2006). Moreover, fMRI suggests that the drug does indeed lead to disturbed prediction error firing (Corlett et al. 2006). We contend that this disturbance is mediated by a ketamine-induced augmentation of pre-synaptic glutamate release and consequent post-synaptic AMPA receptor stimulation. If either of these effects is blocked, the psychotomimetic aspects of ketamine administration are attenuated (Anand et al. 2000; Moghaddam and Adams 1998). That the perceptual aberrations and delusion-like ideas are not directly linked to NMDA blockade but

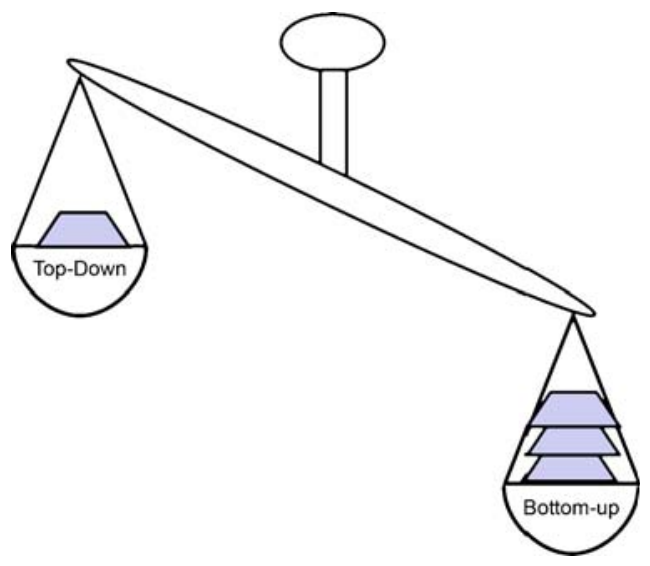

\begin{tabular}{|l|c|c|c|c|}
\hline Manipulation & $\begin{array}{l}\text { Bottom- } \\
\text { up }\end{array}$ & $\begin{array}{l}\text { Top- } \\
\text { down }\end{array}$ & $\begin{array}{l}\text { Delusion-like } \\
\text { ideas }\end{array}$ & Hallucinations \\
\hline Ketamine & & $\downarrow$ & ++ & -- \\
\hline Cannabinoids & $\longleftrightarrow$ & $\downarrow$ & ++ & -- \\
\hline $\begin{array}{l}\text { Amphetamine } \\
\text { (repeated dosing) }\end{array}$ & $\uparrow$ & + & ++ & ++ \\
\hline
\end{tabular}

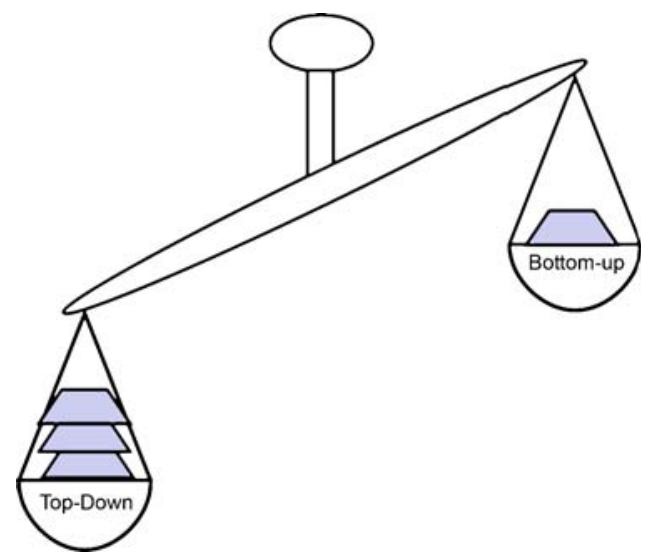

\begin{tabular}{|l|c|c|c|c|}
\hline Manipulation & $\begin{array}{l}\text { Bottom- } \\
\text { up }\end{array}$ & $\begin{array}{l}\text { Top- } \\
\text { down }\end{array}$ & $\begin{array}{l}\text { Delusion-like } \\
\text { ideas }\end{array}$ & Hallucinations \\
\hline $\begin{array}{l}\text { Amphetamine } \\
\text { (single dosing) }\end{array}$ & $\longleftrightarrow$ & $\uparrow$ & + & -- \\
\hline LSD & $\downarrow$ & $\longleftarrow$ & -- & ++ \\
\hline $\begin{array}{l}\text { Sensory } \\
\text { Deprivation }\end{array}$ & $\downarrow$ & $\longleftarrow$ & $?$ & ++ \\
\hline
\end{tabular}

Fig. 2 A summary of the suggested effects of key manipulations used to induce psychosis on bottom-up/top-down balance 
involve a more complex additional mechanism is supported by a recent SPECT study showing that NMDA blockade correlates with the severity of negative rather than positive symptoms (Stone et al. 2008).

To put things more simply in the context of the hierarchical Bayesian model, we suggest that ketamine and PCP disturb the feed-forward mechanism (prediction error signal) through AMPA upregulation and the feedback constraint (priors) through NMDA blockade. We believe that the impairment of NMDA function would limit the extent to which priors could exert their effect in explaining the mismatch that is carried by the upregulated AMPA signalling. This would lead to persistence of perceptual aberrations due in part to persistent AMPA signalling and in part to an attenuation of the constraining effect that priors would normally afford on perception. That is, under ketamine, the subject experiences perceptual aberrations (due to AMPA upregulation) and a reduced capacity to accommodate and ignore these aberrations (due to NMDA blockade). We suggest that this combination leads to the powerful changes in experience and inference that characterise glutamatergic model psychoses. In the following sections, we consider the ways that other drugs produce differing types of imbalance in this feed-forward-feedback system, perhaps accounting for differing effects.

\section{Serotonergic drugs}

LSD and other serotonergic hallucinogens induce profound visual hallucinations, together with altered experiences of time, space and the self (Geyer and Vollenweider 2008). Acute LSD does not appear to induce delusions, at least consistently across subjects (Young 1974), although some subjects do experience a profound paranoia (Cohen 1966). Serotonergic hallucinogens act at 5-HT receptors; however, they also impact upon glutamatergic transmission (Aghajanian and Marek 2000), enhancing glutamatergic responses to sensory stimuli in the locus coeruleus (Rasmussen and Aghajanian 1986). Cortically, 5-HT stimulation enhances excitatory glutamatergic postsynaptic potentials, an effect most pronounced in frontal cortex (Aghajanian and Marek 1997). The effect is blocked by mglur 2/3 agonists (Marek et al. 2000), suggesting that serotonergic hallucinogens induce an increase in presynaptic glutamate release in frontal cortex.

Intriguingly, although LSD alters glutamatergic function, it does not impair NMDA signalling (Aghajanian and Marek 2000) and may actually enhance it (Lambe and Aghajanian 2006). This observation points towards a potential explanation of the different effects of LSD and ketamine on perception. LSD induces visual and auditory hallucinations, while ketamine tends to alter the salience and/or vividness of real percepts rather than inducing hallucinations per se (Corlett et al. 2006, although see Stone and Pilowsky 2006). Within the framework that we have outlined, excessive AMPA signalling in the absence of NMDA impairment would lead to increased sensory noise in the context of normal priors or expectancies. We speculate that impaired bottom-up processing coupled with preserved top-down processing is exactly the combination of conditions in which one would expect hallucinations to occur since a preserved top-down signal imposes structure upon noisy inputs. Put more simply, the persistence and strength of the sensory signal suggest that there is something to be explained, and the preserved top-down structure posits this explanation in terms of a stimulus that gives rise to it: a stimulus that is not actually present. This, in essence, is a hallucination - a percept without a stimulus.

How can we reconcile this account of serotonergic hallucinogens (noisy, unpredictable bottom-up signalling in the context of preserved and perhaps enhanced top-down processing) with the observation that serotonergic hallucinogens do occasionally engender delusion-like ideas? (Cohen 1966) It may be that the delusions engendered by LSD arise from the autoscopic, out of body, experiences that are commonly induced (Salama 1981). That is, under LSD, the hallucination of a double of oneself may lead, for example, to ideas of reference in contrast to ketamine where such ideas emerge from aberrant experiences of external objects events and people (Corlett et al. 2007; Oye et al. 1992). Cohen (1966) suggests this mechanism and there are reported cases that seem to support this, for example, a subject who, on using LSD, perceived himself on television acting as one of the stars (Salama 1981). The experience of a double of oneself also occurs with high frequency during social and sensory deprivation (Mishara 2008) and, with relevance to our model, has been ascribed to an excessively strong top-down expectancy of the presence of others (Hoffman 2007). We shall revisit this theme below when we consider sensory deprivation but conclude this consideration of serotonergic hallucinations and bodily delusions in the Bayesian framework by attributing them to bottom-up noise in the face of enhanced top-down expectancy (Blanke et al. 2004).

A relative excess of top-down influence has previously been hypothesised to underlie hallucinatory behaviour. Grossberg, for example, emphasises the role of dopaminedriven motivational processes in the shift towards top-down influences (Grossberg 2000), while Collerton and colleagues suggest that due to cholinergic and dopaminergic dysfunctions, top-down inferences pre-dominate and induce recurrent visual hallucinations (Collerton et al. 2005). Our account encompasses both of these possibilities, but emphasises the role of more fundamental ascending and descending glutamatergic projections. 


\section{Cannabinoids}

There is not a single, elementary manifestation of mental illness that cannot be found in the mental changes induced by hashish. (Moreau 1845/1973)

In the 1980s, an endogenous cannabinoid system was identified in the mammalian brain (Devane et al. 1988, 1992). Cannabinoid receptors (Matsuda et al. 1990), endogenous ligands (Devane et al. 1992), second messenger systems (Stella et al. 1997) and cannabinoid receptor antagonists (Rinaldi-Carmona et al. 1994) were identified. Furthermore, synthetic $\Delta-9$-THC was shown to have psychotomimetic effects in healthy volunteers (D'Souza et al. 2004). Like ketamine, $\Delta$-9-THC induces dopamine release in the healthy human striatum; however, across subjects, the elevation in dopamine release does not correlate with the subjective effects of the drug (Bossong et al. 2008). Furthermore, haloperidol does not reverse the psychotomimetic effects of $\Delta$-9-THC in healthy volunteers (D'Souza et al. 2008).

Within the current framework, a clue to the action of the $\Delta$-9-THC comes from its impact upon a visual illusion held to depend on the interaction between top-down expectancies and bottom-up experiences: the binocular depth inversion illusion (BDII; Emrich 1989; Koethe et al. 2006). This is a visual illusion wherein an object that is actually concave is seen as convex, e.g. a hollow, concave, face mask will continue to be experienced as convex, an experience which, although objectively wrong, is the expected and more plausible percept. This illusion is thought to occur through a top-down, internal mechanism, which corrects implausible data so they conform to more plausible hypotheses. In chronic cannabis users, individuals with schizophreniform psychosis, those in a prodromal psychotic state and healthy volunteers who administered $\Delta$ 9-THC, the BDII is attenuated (Koethe et al. 2006; Semple et al. 2003). This suggests an effect of active psychosis and cannabinoid signalling on top-down correction of perception (Emrich et al. 1991; Schneider et al. 1996).

In contrast to THC, ketamine has no effect on the BDII, despite inducing perceptual changes and psychotic symptoms (Passie et al. 2003). This raises the intriguing possibility that the effects on perception of the two drugs are dissociable: Ketamine has a pre-dominant impact on bottom-up AMPA signalling in contrast to the pre-dominant top-down effect THC suggested above. $\triangle 9$-THC increases pre-frontal glutamate release (Pistis et al. 2002), like ketamine. However, in the hippocampus, cannabinoids act pre-synaptically to inhibit $\mathrm{Ca}^{2+}$-induced release of glutamate and acetylcholine (Fujiwara and Egashira 2004). We have argued that these two neurotransmitters are intimately involved in the specification of priors, and in the absence of strong priors, one would predict a weaker BDII and a weaker influence of top-down processes (Fig. 2f). As mentioned above, this weakening of top-down influences would suggest that hallucinations should not pre-dominate under $\triangle 9$-THC administration, and this appears to be the case, however, that delusion-like ideas would be predicted, and this is borne out by studies exploring the impact of THC on healthy volunteers (D'Souza et al. 2004).

\section{Dopamine agonists}

With some caveats, dopamine remains at the forefront of neurotransmitter systems implicated in the positive symptoms of psychosis. Explanatory models inspired by dopamine's role in learning and motivation have been proposed to account for the positive symptoms of psychosis (Beninger 1988; Corlett et al. 2007; Gray 2004; Kapur 2003; Miller 1976). Amphetamine elevates dopamine levels in the striatum in healthy volunteers and more so in individuals with schizophrenia (Laruelle et al. 2003). The magnitude of dopamine release in remitted patients correlates with the severity of symptom relapse experienced (Laruelle et al. 1999). After King et al. (1984), Shaner (1999) offered an explanation of the delusions induced by amphetamine administration, which appealed to a chaotic increase in mesocorticolimbic dopamine, driving superstitious behaviours akin to those seen in experimental animals undergoing instrumental learning (King et al. 1984; Shaner 1999; Skinner 1948).

Kapur (2003) suggested that amphetamines and endogenous psychotic states were associated with an increase in striatal dopamine and that this increase led to the inappropriate attribution of motivational salience to stimuli, thoughts and percepts (Kapur 2003). Salience is a concept derived from the addiction literature (Berridge and Robinson 2003), and it refers to the capacity for stimuli and events to grab attention and drive action. According to Kapur, hallucinations and delusions result from dopaminedriven attribution of inappropriate salience to internal and external stimuli.

Acute amphetamine administration increases striatal dopamine release in healthy humans (Laruelle et al. 1995, 1999), and the elegant positron emission tomography experiments of Kegeles and colleagues demonstrate that ketamine pre-treatment enhances this effect (Kegeles et al. 2000). This suggests that amphetamine-induced dopamine release may be under glutamatergic control. This suggestion was confirmed in primates administered with amphetamine: PET showed that amphetamine-induced dopamine release was blocked by a metabotropic glutamate receptor agonist (van Berckel et al. 2006). That is, it appears that that acute administration of amphetamine increases dopamine release by increasing pre-synaptic glutamate release (Krystal 2008). 
However, a single amphetamine does not induce delusionlike ideas of the same intensity as ketamine and cannabis (as we discuss below, repeated dosing is another matter). Rather, elevated mood, grandiose ideas and hyperactivity are more characteristic (Jacobs and Silverstone 1986). It also increases perceptual acuity of the whole visual field (Fillmore et al. 2005), unlike ketamine, which enhances the salience of discrete and apparently random objects, events and stimuli (Corlett et al. 2007; Oye et al. 1992). We suggest that this pattern of psychopathology is due to increased confidence in actual perceptual inputs and predictions through enhanced dopaminergic (Laruelle et al. 1995, 1999) and cholinergic function (Acquas and Fibiger 1998).

Speculation on the role of dopamine in confidence and certainty derives from a further consideration of the temporal characteristics of midbrain dopamine firing as well as an appreciation of the role of dopamine in the placebo effect. Whilst dopamine neurons in the midbrain appear to code a simple mismatch between expectancy and experience (Rescorla and Wagner 1972; Waelti et al. 2001), their firing has other important properties. Notably, the response that was originally invoked by a reward tracks backwards in time, occurring in response to the environmental cue that best predicts the reward (Schultz 1998). This may be a neural signature of stimulus substitution (Pavlov 1928), representing an expectancy or anticipation of reward to come and perhaps indicating the necessity for preparatory behaviours such as approach (Robbins and Everitt 2007).

This expectation process has been strongly implicated in the placebo effect, the observation that inert compounds can have clinical efficacy in individuals who strongly expect to experience therapeutic benefits (Oken 2008); furthermore, such expectations also influence visual perception (Sterzer et al. 2008). In addition, a sense of lack of control, which presumably is associated with an elevation in uncertainty, renders healthy individuals more likely to experience patterns in random data (a tendency which may relate directly to hallucinations; Whitson and Galinsky 2008). Critically, dopamine has been implicated in the placebo response. Subjects who have higher striatal dopamine levels show stronger anticipatory responses during reward learning and a stronger placebo response to what they believed were anti-nociceptive preparations (Scott et al. 2007). Based on these data, one might expect that elevating dopamine levels with amphetamine would enhance the strength of anticipatory top-down expectation. However, dopamine also enhances the signal-to-noise ratio of perceptual inputs (Spitzer 1995; Spitzer and Walter 2003). This would increase the extent to which a bottom-up signal matches a strong top-down expectancy, leading to increased confidence in the capacity to predict and control the environment. This may manifest as increased perceptual clarity, cognitive capabilities and, potentially, grandiosity rather than hallucinations and delusions of reference.
A richer pattern of psychopathology is induced through repeated amphetamine administration. This includes behaviour suggesting hallucinations in primates chronically administered amphetamines (Castner and Goldman-Rakic 1999, 2003) and a full-blown psychotic illness (including profound delusions and hallucinations) in humans. It is noteworthy therefore that repeated administration of amphetamine to humans alters striatal responsivity (Boileau et al. 2006). Animal models suggest that this may be due to changes in the morphology of dendritic spines in striatal medium spiny neurons (Waltz et al. 2007), altered expression of NMDA and AMPA receptors ( $\mathrm{Lu}$ et al. 1997; Lu and Wolf 1999) and changes in pre-frontal cholinergic function (Sarter et al. 2005, 2008). All of the above processes would alter the function of the Bayesian system we describe through an AMPA/NMDA imbalance with a corresponding change in the delicate balance between bottom-up and top-down signalling. In this case, we would predict that the effect would be more akin to (though perhaps more profound than) an acute dose of PCP or ketamine, with an impairment in both bottom-up and topdown signalling.

We can contrast this picture with that hypothesised for ketamine above, in which we suggested that excessive AMPA transmission in the presence of NMDA blockade leads to characteristic delusion-like ideas and perceptual illusions. Repeated amphetamine administration would also engender aberrant feed-forward AMPA-mediated prediction error, but now in the context of a sensitised dopamine system, prone to excessive and inappropriate dopamine (and subsequent acetylcholine) release in response to nonsalient events (Nelson et al. 2002). Since these slower transmitters are critical in specifying top-down perceptual and attentional priors Collerton et al. 2005; Friston 2005b), their inappropriate registration confers a sensory expectancy when there should be none, engendering hallucinations proper rather than the odd perceptions characteristic of ketamine (Pomarol-Clotet et al. 2006).

Sensory deprivation: a non-drug model of psychosis

\section{The impact of sensory deprivation on psychosis and psychotogenic drug effects}

We have outlined a Bayesian account of the psychotomimetic effects of various drug manipulations. But, of course, the system may be perturbed in other ways. For example, if we reduce sensory input while individuals are under the influence of psychotomimetic drugs, at least some of the psychotogenic properties of these compounds should be changed. This is indeed the case. Lawes (1963) investigated the psychopathology induced by PCP under three levels of sensory stimulation: (1) normal social interaction with a 
psychologist in an interviewing room; (2) in a soundproofed cubicle under conditions of maximum sensory deprivation (with gloves to block tactile input), opaque goggles and lights turned out to attenuate visual inputs; and finally, (3) social isolation (in the deprivation chamber but without gloves and goggles and with the lights on). Condition (1), social interaction, led to the strongest psychopathological reactions. Condition (3), social but not sensory deprivation, induced an intermediate reaction. The weakest response to PCP was observed while subjects were under maximal sensory and social deprivation (condition (2); Lawes 1963).

These findings corroborate observations made on patients with schizophrenia in sensory deprivation. Harris (1959) found that patients with schizophrenia tolerated 30 min of sensory deprivation much better than controls. Five of 12 patients failed to complete a further $2 \mathrm{~h}$ of deprivation (three due to boredom and two due to enhancement of symptom severity). Many of the remaining subjects felt a therapeutic benefit, in particular an attenuation of auditory hallucinations (Harris 1959). We will return to the interactions of $\mathrm{PCP}$ and schizophrenia and sensory deprivation below, after considering the effects of sensory deprivation alone.

\section{Sensory deprivation alone}

In the absence of a psychotomimetic compound, sensory deprivation alone can act as a model of psychosis in psychiatrically healthy individuals (Rosenzweig 1959). Explorers (Byrd 1938) and prisoners of war (Worden 1954), subjected to extended periods of sensory and social isolation, describe changes in their experiences and cognition comparable to those induced by pharmacological intervention with psychotomimetic drugs (Luby et al. 1959). Experimental isolation and sensory deprivation of student volunteers led to changes in concentration, affective disturbances, vivid visual, auditory and tactile hallucinations and delusions (Bexton et al. 1954; Scott et al. 2007).

How can deprivation have such contradictory effects in healthy individuals and those experiencing psychosis (pharmacological or endogenous)? Within the framework of the Bayesian model, we suggest that a healthy individual under sensory deprivation experiences a lack of bottom-up sensory stimulation. Since sensory stimulation is normally much greater, the predictions of higher brain regions are violated. In addition, sensory deprivation by physical means is never complete and there are baseline, noisy, fluctuations in firing in the brain. In other words, the sensorially deprived state involves low-level noisy bottomup signals combined with strong priors that are accustomed to acting upon stronger signals. The top-down, NMDAbased, descending projections attempt to impose some structure upon their noisy and much-reduced inputs. Thus, just as with pharmacologically modelled psychoses (particularly serotonergic models - see above), there are prediction errors and noisy signals treated as genuine inputs by higher levels in the hierarchy. The consequence of this would be hallucinations.

The delusions characteristic of sensory isolation tend to involve autoscopic experiences of other presences in the isolation chamber, which induce paranoia and feelings of being observed (Bexton et al. 1954; Scott et al. 2007). Such phenomena might arise from a strong top-down expectancy of the presence of other people, which might pre-dominate even in isolation leading to the strong sense of another person in the isolation chamber perhaps inducing paranoia (Hoffman 2007). Indeed, the paranoia and hallucinations experienced in sensory deprivation, which we argue are resultant from bottom-up noise in the face of preserved (or even relatively enhanced) top-down mechanisms, may share phenomenological and biological similarities with the serotonergic hallucinogens discussed above. Both sets of phenomena occur when the top-down system imposes structure on noisy, unpredictable bottom-up signals.

In support of this 'imposition of structure on noise' interpretation, Rosenzweig and Gardner (1966) observed much milder psychopathology in individuals subjected to tactile and visual deprivation but exposed to structured, meaningful, auditory inputs (tapes of jokes, stories and plays) compared with individuals similarly deprived of tactile and visual inputs and additionally played meaningless white noise or the same tapes played in reverse (Rosenzweig and Gardner 1966). Interestingly, hallucinations in schizophrenia appear to get worse when sensory input is noisier (Margo et al. 1981).

These observations may help to explain the apparently paradoxical pro-psychotic effects of sensory deprivation in non-psychotic individuals and the anti-psychotic effects in actively psychotic subjects. In individuals suffering from drug-induced or endogenous psychotic symptoms, sensory deprivation may provide respite from excessive feedforward activation in the Bayesian hierarchy (which we attribute to increased and inappropriate AMPA receptor stimulation). Essentially, when sensory stimulation is reduced, in psychotic people, perhaps the strength of the aberrant bottom-up signal is attenuated, relieving the topdown prediction system and reducing the tendency to try to impose structure on meaningless noise. Put simply, perhaps the over-rich sensory experience of the psychotic person is temporarily assuaged by sensory deprivation. However, as Harris (1959) observed, sensory deprivation was propsychotic in some patients, and baseline schizotypal traits seem to predispose individuals towards more severe positive symptoms during sensory deprivation (McCreery and Claridge 1996). Perhaps this observation that a 
tendency to experience psychosis occurs in some individuals but not others is reflective of variability in top-down information processing biases.

Visual sensory deprivation (by occluding the eyes) results in changes in glutamatergic function. Specifically, in the context of the above, it is worth noting that sensory deprivation increases pre-synaptic glutamate release (Yashiro et al. 2005), perhaps as a consequence of the prediction errors induced by sensory inputs that are lower than expected, which would then engage top-down inference mechanisms. Accompanying this enhanced glutamate release, there are changes in metabotropic glutamate receptor activity and concomitant changes in synaptic plasticity (Van Keuren-Jensen and Cline 2006). Perhaps this provides a further neurochemical basis for understanding the ameliorating effects of sensory deprivation on psychotic individuals. That is, the increase in mGluR function associated with sensory deprivation might counteract the mGluR alteration of psychosis. In this regard, it is noteworthy that an mGlur agonist has recently shown promising results as an anti-psychotic in patients with schizophrenia (Patil et al. 2007). Our theory suggests that pre-treating healthy individuals with the mGlur agonist before sensory deprivation should attenuate the psychotogenic effects (since the agonist should decrease noisy AMPA transmission below baseline). Furthermore, enhancing NMDA receptor function (for example with dcycloserine) in advance of deprivation should enhance the psychotomimetic effect in healthy individuals since NMDA receptors provide the priors, which are imposed even in the absence of stimulation.

There is another non-drug model of psychosis, namely sleep deprivation. Sleep deprivation alters dopamine turnover in the striatum (Volkow et al. 2009) as well as NMDA and AMPA function in pre-frontal cortex (Szabo et al. 2009). Phenomenologically, sleep deprivation appears to engender a manic state, not unlike acute amphetamine (Milad et al. 2007; Tyler 1955); furthermore, it has an impact on the BDII: Sleep-deprived individuals perceive the hollow mask as hollow (Schneider et al. 1996), suggesting an impairment of top-down processing. Chronic amphetamine abuse is also associated with sleep deprivation (Williamson et al. 1997). The additional, top-down processing impairment mediated by sleep disturbance may provide another mechanism, in addition to neuroplastic sensitization, through which the more profound psychopathology associated with chronic amphetamine use may arise.

\section{Limitations}

In trying to relate the main models of psychosis to their predominant effects, we have taken a necessarily simplified view of the balance between prior beliefs and bottom-up signal in the form of prediction error. First, we have alluded to the Bayesian hierarchical structure, but have largely confined our discussion to a consideration of the interactions only at a single level. This neglects the likelihood that, as one moves from basic sensory processing through to the highest levels of inference and belief, the top-down/ bottom-up interactions perhaps encode different features of our signals about the world. One distinction that we have drawn only briefly in this paper is between the strength of the signal and our confidence in its value (see Fletcher and Frith 2009). One possibility is that lower levels in the hierarchy are more concerned with the signal-to-noise ratio, while higher levels are more concerned with the overall confidence in the signals. We believe that a more in-depth consideration of this distinction, in the setting of psychosis, will be very useful in the future.

\section{Conclusions}

To summarise, we have outlined a cognitive neuroscience framework of perception and learning that we have used to explain the psychotomimetic effects of a number of model psychoses. We have attempted to do so in a way that crosses levels of explanation (Marr 1982) in order to allow a meaningful consideration of the symptoms of psychosis, the computational cognitive processes that might be key to understanding them and the neurobiological implementation of these processes,

Our framework is grounded in Bayes rule but has much in common with formal animal learning theory (Courville et al. 2006; Kruschke et al. 2005). At its core is the notion that much of what we perceive is based on our expectations (Helmholtz 1871/1971) that perceptual expectations are learned (Barlow 1990; Pavlov 1928) and that mismatches between what we expect and what we experience drive updating of our expectancies (Friston 2005a). The psychotic process can and should, we argue, be understood in terms of precise disturbances in this system. Common to the transiently induced psychosis-like states in humans are pharmacological (and occasionally non-pharmacological) interventions that impact upon, the prediction error, the priors and the subsequent updating process. The specific pattern of psychopathology that each model induces can be explained by its relative impact upon these three processes. We find that the model provides an explanation of the observation that drugs with apparently disparate pharmacological targets can have apparently similar psychotomimetic effects.

Our attempt to explain the psychotic symptoms rests critically on the role of glutamatergic processes in mediating bottom-up and top-down processing (via AMPA and NMDA receptors, respectively) as well as the roles of 
slower, neuromodulatory, transmitters in modulating topdown expectancies. To speculate a little further, one possible means of interaction between these slow and fast processes lies in the modulation of membrane potassium channel conductances, which would change the membrane potential and hence susceptibility to excitation by incoming signals (Fiorillo et al. 2003). Dopamine and acetylcholine modulate these conductances (McCormick et al. 1993). Moreover, recently, the hallucinogen $\mathrm{N}, \mathrm{N}$-dimethyltryptamine (DMT) has been shown to modulate sigma receptors and, in so doing, to alter potassium channel conductances (Fontanilla et al. 2009). We wish to highlight the utility of our proposed Bayesian framework in bringing together disparate psychotomimetic preparations and revealing a potential unifying neurophysiological process. The modulation of membrane potassium channel conductance may provide a novel therapeutic target for the positive symptoms of psychosis; indeed, retigabine, a drug which opens potassium channels, has recently been reported to have antipsychotic like effects (Sotty et al. 2009).

A consideration of aberrations of the dynamic interactions between sensation, expectation, inference and learning provide a framework to understand how pharmacological interventions can alter neural responses and hence change conscious experiences, inducing the apparent disconnection from reality that is characteristic of psychosis.

Acknowledgements PCF is supported by the Bernard Wolfe Health Neuroscience fund and the Wellcome Trust. PRC is a University of Cambridge Parke-Davis Exchange Fellow. CDF is supported by the Danish National Research Foundation.

Open Access This article is distributed under the terms of the Creative Commons Attribution Noncommercial License which permits any noncommercial use, distribution, and reproduction in any medium, provided the original author(s) and source are credited.

\section{References}

Acquas E, Fibiger HC (1998) Dopaminergic regulation of striatal acetylcholine release: the critical role of acetylcholinesterase inhibition. J Neurochem 70:1088-1093

Aghajanian GK, Marek GJ (1997) Serotonin induces excitatory postsynaptic potentials in apical dendrites of neocortical pyramidal cells. Neuropharmacology 36:589-599

Aghajanian GK, Marek GJ (2000) Serotonin model of schizophrenia: emerging role of glutamate mechanisms. Brain Res Brain Res Rev 31:302-312

Anand A, Charney DS, Oren DA, Berman RM, Hu XS, Cappiello A, Krystal JH (2000) Attenuation of the neuropsychiatric effects of ketamine with lamotrigine: support for hyperglutamatergic effects of N-methyl-D-aspartate receptor antagonists. Arch Gen Psychiatry $57: 270-276$

Angelucci A, Levitt JB, Lund JS (2002a) Anatomical origins of the classical receptive field and modulatory surround field of single neurons in macaque visual cortical area V1. Prog Brain Res 136:373-388

Angelucci A, Levitt JB, Walton EJ, Hupe JM, Bullier J, Lund JS (2002b) Circuits for local and global signal integration in primary visual cortex. J Neurosci 22:8633-8646

Anis NA, Berry SC, Burton NR, Lodge D (1983) The dissociative anaesthetics, ketamine and phencyclidine, selectively reduce excitation of central mammalian neurones by N-methylaspartate. Br J Pharmacol 79:565-575

Bao S, Chan VT, Merzenich MM (2001) Cortical remodelling induced by activity of ventral tegmental dopamine neurons. Nature 412:79-83

Bar-Gad I, Bergman H (2001) Stepping out of the box: information processing in the neural networks of the basal ganglia. Curr Opin Neurobiol 11:689-695

Bar-Gad I, Havazelet-Heimer G, Goldberg JA, Ruppin E, Bergman H (2000) Reinforcement-driven dimensionality reduction-a model for information processing in the basal ganglia. J Basic Clin Physiol Pharmacol 11:305-320

Bar-Gad I, Morris G, Bergman H (2003) Information processing, dimensionality reduction and reinforcement learning in the basal ganglia. Prog Neurobiol 71:439-473

Barlow H (1990) Conditions for versatile learning, Helmholtz's unconscious inference, and the task of perception. Vision Res 30:1561-1571

Bartlett FC (1932) Remembering Cambridge University Press, Cambridge University Press

Beninger RJ (1988) The slow therapeutic action of antipsychotic drugs: a possible mechanism involving the role of dopamine in incentive learning. Karger, Basal

Berridge KC, Robinson TE (2003) Parsing reward. Trends Neurosci 26:507-513

Bexton WH, Heron W, Scott RH (1954) Effects of decreased variation in the sensory environment. Can J Psychol 8:70-76

Blanke O, Landis T, Spinelli L, Seeck M (2004) Out-of-body experience and autoscopy of neurological origin. Brain 127:243-258

Boileau I, Dagher A, Leyton M, Gunn RN, Baker GB, Diksic M, Benkelfat C (2006) Modeling sensitization to stimulants in humans: an [11C]raclopride/positron emission tomography study in healthy men. Arch Gen Psychiatry 63:1386-1395

Bossong MG, van Berckel BN, Boellaard R, Zuurman L, Schuit RC, Windhorst AD, van Gerven JM, Ramsey NF, Lammertsma AA, Kahn RS (2008) Delta9-Tetrahydrocannabinol Induces Dopamine Release in the Human Striatum. Neuropsychopharmacology 41:T57

Bowdle TA, Radant AD, Cowley DS, Kharasch ED, Strassman RJ, Roy-Byrne PP (1998) Psychedelic effects of ketamine in healthy volunteers: relationship to steady-state plasma concentrations. Anesthesiology 88:82-88

Breier A, Adler CM, Weisenfeld N, Su TP, Elman I, Picken L, Malhotra AK, Pickar D (1998) Effects of NMDA antagonism on striatal dopamine release in healthy subjects: application of a novel PET approach. Synapse 29:142-147

Buchel C, Friston KJ (1997) Modulation of connectivity in visual pathways by attention: cortical interactions evaluated with structural equation modelling and fMRI. Cereb Cortex 7:768-778

Byrd R (1938) Alone. Putnam, New York

Castner SA, Goldman-Rakic PS (1999) Long-lasting psychotomimetic consequences of repeated low-dose amphetamine exposure in rhesus monkeys. Neuropsychopharmacology 20:10-28

Castner SA, Goldman-Rakic PS (2003) Amphetamine sensitization of hallucinatory-like behaviors is dependent on prefrontal cortex in nonhuman primates. Biol Psychiatry 54:105-110

Cohen S (1966) A classification of LSD complications. Psychosomatics 7:182-186

Collerton D, Perry E, McKeith I (2005) Why people see things that are not there: a novel Perception and Attention Deficit model for 
recurrent complex visual hallucinations. Behav Brain Sci 28:737-757 discussion 757-94

Corlett PR, Aitken MR, Dickinson A, Shanks DR, Honey GD, Honey RA, Robbins TW, Bullmore ET, Fletcher PC (2004) Prediction error during retrospective revaluation of causal associations in humans: fMRI evidence in favor of an associative model of learning. Neuron 44:877-888

Corlett PR, Honey GD, Aitken MR, Dickinson A, Shanks DR, Absalom AR, Lee M, Pomarol-Clotet E, Murray GK, McKenna PJ, Robbins TW, Bullmore ET, Fletcher PC (2006) Frontal responses during learning predict vulnerability to the psychotogenic effects of ketamine: linking cognition, brain activity, and psychosis. Arch Gen Psychiatry 63:611-621

Corlett PR, Honey GD, Fletcher PC (2007) From prediction error to psychosis: ketamine as a pharmacological model of delusions. J Psychopharmacol 21:238-252

Courville AC, Daw ND, Touretzky DS (2006) Bayesian theories of conditioning in a changing world. Trends Cogn Sci 10:294-300

D'Souza DC, Perry E, MacDougall L, Ammerman Y, Cooper T, Wu YT, Braley G, Gueorguieva R, Krystal JH (2004) The psychotomimetic effects of intravenous delta-9-tetrahydrocannabinol in healthy individuals: implications for psychosis. Neuropsychopharmacology 29:1558-1572

D'Souza DC, Braley G, Blaise R, Vendetti M, Oliver S, Pittman B, Ranganathan M, Bhakta S, Zimolo Z, Cooper T, Perry E (2008) Effects of haloperidol on the behavioral, subjective, cognitive, motor, and neuroendocrine effects of Delta-9-tetrahydrocannabinol in humans. Psychopharmacology (Berl) 198:587-603

den Ouden HE, Friston KJ, Daw ND, McIntosh AR, Stephan KE (2009) A dual role for prediction error in associative learning. Cereb Cortex 19:1175-1185

Deneve S (2008a) Bayesian spiking neurons I: inference. Neural Comput 20:91-117

Deneve S (2008b) Bayesian spiking neurons II: learning. Neural Comput 20:118-145

Devane WA, Dysarz FA 3rd, Johnson MR, Melvin LS, Howlett AC (1988) Determination and characterization of a cannabinoid receptor in rat brain. Mol Pharmacol 34:605-613

Devane WA, Breuer A, Sheskin T, Jarbe TU, Eisen MS, Mechoulam R (1992) A novel probe for the cannabinoid receptor. J Med Chem 35:2065-2069

Emrich HM (1989) A three-component-system hypothesis of psychosis. Impairment of binocular depth inversion as an indicator of a functional dysequilibrium. Br J Psychiatry Suppl: 37-39

Emrich HM, Weber MM, Wendl A, Zihl J, von Meyer L, Hanisch W (1991) Reduced binocular depth inversion as an indicator of cannabis-induced censorship impairment. Pharmacol Biochem Behav 40:689-690

Fillmore MT, Rush CR, Abroms BD (2005) d-Amphetamine-induced enhancement of inhibitory mechanisms involved in visual search. Exp Clin Psychopharmacol 13:200-208

Fiorillo CD (2008) Towards a general theory of neural computation based on prediction by single neurons. PLoS ONE 3: e3298

Fiorillo CD, Tobler PN, Schultz W (2003) Discrete coding of reward probability and uncertainty by dopamine neurons. Science 299:1898-1902

Fleminger S (1992) Seeing is believing: the role of 'preconscious' perceptual processing in delusional misidentification. $\mathrm{Br} \mathrm{J}$ Psychiatry 160:293-303

Fletcher PC, Frith CD (2008) Perceiving is believing: a Bayesian approach to explaining the positive symptoms of schizophrenia. Nat Rev Neurosci 10:48-58

Fletcher PC, Frith CD (2009) Perceiving is believing: a Bayesian approach to explaining the positive symptoms of schizophrenia. Nat Rev Neurosci 10:48-58
Fletcher PC, Anderson JM, Shanks DR, Honey R, Carpenter TA, Donovan T, Papadakis N, Bullmore ET (2001) Responses of human frontal cortex to surprising events are predicted by formal associative learning theory. Nat Neurosci 4:1043-1048

Fontanilla D, Johannessen M, Hajipour AR, Cozzi NV, Jackson MB, Ruoho AE (2009) The hallucinogen N, N-dimethyltryptamine (DMT) is an endogenous sigma-1 receptor regulator. Science 323:934-937

Freedman BJ (1974) The subjective experience of perceptual and cognitive disturbances in schizophrenia. A review of autobiographical accounts. Arch Gen Psychiatry 30:333-340

Friston K (2005a) A theory of cortical responses. Philos Trans R Soc Lond B Biol Sci 360:815-836

Friston K (2005b) Hallucinations as perceptual Inference (comment on Collerton et al [2005]). Behav Brain Sci 28:764-766

Fujiwara M, Egashira N (2004) New perspectives in the studies on endocannabinoid and cannabis: abnormal behaviors associate with CB1 cannabinoid receptor and development of therapeutic application. J Pharmacol Sci 96:362-366

Garety PA, Kuipers L, Fowler D, Chamberlain F, Dunn G (1994) Cognitive behavioural therapy for drug-resistant psychosis. Br J Med Psychol 67(Pt 3):259-271

Geyer MA, Vollenweider FX (2008) Serotonin research: contributions to understanding psychoses. Trends Pharmacol Sci 29:445-453

Grace AA (1991) Phasic versus tonic dopamine release and the modulation of dopamine system responsivity: a hypothesis for the etiology of schizophrenia. Neuroscience 41:1-24

Gray JA (2004) On biology, phenomenology, and pharmacology in schizophrenia. Am J Psychiatry 161:377 author reply 377-8

Gray JA, Feldon J, Rawlins JNP, Hemsley D, Smith AD (1991) The neuropsychology of schizophrenia. Behav Brain Sci 14:1-84

Grossberg S (2000) How hallucinations may arise from brain mechanisms of learning, attention, and volition. J Int Neuropsychol Soc 6:583-592

Harris A (1959) Sensory deprivation and schizophrenia. J Ment Sci 105:235-237

Helmholtz H (1871/1971) The facts of perception. In: Russell K (ed) Selected writings of Hermann von Helmholtz. Wesleyan University Press, Connecticut

Hemsley DR, Garety PA (1986) The formation and maintenance of delusions: a Bayesian analysis. Br J Psychiatry 149:51-56

Herrero JL, Roberts MJ, Delicato LS, Gieselmann MA, Dayan P, Thiele A (2008) Acetylcholine contributes through muscarinic receptors to attentional modulation in V1. Nature 454:1110-1114

Hilgetag CC, Burns GA, O'Neill MA, Scannell JW, Young MP (2000) Anatomical connectivity defines the organization of clusters of cortical areas in the macaque monkey and the cat. Philos Trans R Soc Lond B Biol Sci 355:91-110

Hoffman RE (2007) A social deafferentation hypothesis for induction of active schizophrenia. Schizophr Bull 33:1066-1070

Hudson LA, Rollins YD, Anderson CA, Johnston-Brooks C, Tyler KL, Filley CM (2008) Reduplicative paramnesia in Morvan's syndrome. J Neurol Sci 267:154-157

Jackson ME, Homayoun H, Moghaddam B (2004) NMDA receptor hypofunction produces concomitant firing rate potentiation and burst activity reduction in the prefrontal cortex. Proc Natl Acad Sci U S A 101:8467-8472

Jacobs D, Silverstone T (1986) Dextroamphetamine-induced arousal in human subjects as a model for mania. Psychol Med 16:323-329

Javitt DC, Zukin SR (1991) Recent advances in the phencyclidine model of schizophrenia. Am J Psychiatry 148:1301-1308

Kandel ER (1999) Biology and the future of psychoanalysis: a new intellectual framework for psychiatry revisited. Am J Psychiatry 156:505-524

Kapur S (2003) Psychosis as a state of aberrant salience: a framework linking biology, phenomenology, and pharmacology in schizophrenia. Am J Psychiatry 160:13-23 
Kapur S, Seeman P (2001) Ketamine has equal affinity for NMDA receptors and the high-affinity state of the dopamine D2 receptor. Biol Psychiatry 49:954-957

Kegeles LS, Abi-Dargham A, Zea-Ponce Y, Rodenhiser-Hill J, Mann JJ, Van Heertum RL, Cooper TB, Carlsson A, Laruelle M (2000) Modulation of amphetamine-induced striatal dopamine release by ketamine in humans: implications for schizophrenia. Biol Psychiatry 48:627-640

King R, Barchas JD, Huberman BA (1984) Chaotic behavior in dopamine neurodynamics. Proc Natl Acad Sci U S A 81:1244-1247

Koethe D, Gerth CW, Neatby MA, Haensel A, Thies M, Schneider U, Emrich HM, Klosterkotter J, Schultze-Lutter F, Leweke FM (2006) Disturbances of visual information processing in early states of psychosis and experimental delta-9-tetrahydrocannabinol altered states of consciousness. Schizophr Res 88:142-150

Kornhuber J (1990) Glutamate and schizophrenia. Trends Pharmacol Sci $11: 357$

Kruschke JK (2008) Bayesian approaches to associative learning: from passive to active learning. Learn Behav 36:210-226

Kruschke JK, Kappenman ES, Hetrick WP (2005) Eye gaze and individual differences consistent with learned attention in associative blocking and highlighting. J Exp Psychol Learn Mem Cogn 31:830-845

Krystal JH (2008) Capitalizing on extrasynaptic glutamate neurotransmission to treat antipsychotic-resistant symptoms in schizophrenia. Biol Psychiatry 64:358-360

Krystal JH, Karper LP, Seibyl JP, Freeman GK, Delaney R, Bremner JD, Heninger GR, Bowers MB Jr, Charney DS (1994) Subanesthetic effects of the noncompetitive NMDA antagonist, ketamine, in humans. Psychotomimetic, perceptual, cognitive, and neuroendocrine responses. Arch Gen Psychiatry 51:199-214

Krystal JH, D'Souza DC, Karper LP, Bennett A, Abi-Dargham A, Abi-Saab D, Cassello K, Bowers MB Jr, Vegso S, Heninger GR, Charney DS (1999) Interactive effects of subanesthetic ketamine and haloperidol in healthy humans. Psychopharmacology (Berl) 145:193-204

Lambe EK, Aghajanian GK (2006) Hallucinogen-induced UP states in the brain slice of rat prefrontal cortex: role of glutamate spillover and NR2B-NMDA receptors. Neuropsychopharmacology 31:1682-1689

Laruelle M, Abi-Dargham A, van Dyck CH, Rosenblatt W, Zea-Ponce Y, Zoghbi SS, Baldwin RM, Charney DS, Hoffer PB, Kung HF et al (1995) SPECT imaging of striatal dopamine release after amphetamine challenge. J Nucl Med 36:1182-1190

Laruelle M, Abi-Dargham A, Gil R, Kegeles L, Innis R (1999) Increased dopamine transmission in schizophrenia: relationship to illness phases. Biol Psychiatry 46:56-72

Laruelle M, Kegeles LS, Abi-Dargham A (2003) Glutamate, dopamine, and schizophrenia: from pathophysiology to treatment. Ann N Y Acad Sci 1003:138-158

Lavin A, Nogueira L, Lapish CC, Wightman RM, Phillips PE, Seamans JK (2005) Mesocortical dopamine neurons operate in distinct temporal domains using multimodal signaling. J Neurosci 25:5013-5023

Law CT, Gold JI (2009) Reinforcement learning can account for associative and perceptual learning on a visual-decision task. Nat Neurosci 12:655

Lawes TGC (1963) Schizophrenia, 'sernyl' and sensory deprivation. Br J Psychiatr 109:243-250

Lisman JE, Grace AA (2005) The hippocampal-VTA loop: controlling the entry of information into long-term memory. Neuron 46:703713

Lorincz A (1997) Common control principles of basal gangliathalamocortical loops and the hippocampus. Neural Network World 6:649-677
Lu W, Wolf ME (1999) Repeated amphetamine administration alters AMPA receptor subunit expression in rat nucleus accumbens and medial prefrontal cortex. Synapse 32:119-131

Lu W, Chen H, Xue CJ, Wolf ME (1997) Repeated amphetamine administration alters the expression of mRNA for AMPA receptor subunits in rat nucleus accumbens and prefrontal cortex. Synapse 26:269-280

Luby ED, Cohen BD, Rosenbaum G, Gottlieb JS, Kelley R (1959) Study of a new schizophrenomimetic drug; sernyl. AMA Arch Neurol Psychiatry 81:363-369

Lyons A, Kashima Y (2003) How are stereotypes maintained through communication? The influence of stereotype sharedness. J Pers Soc Psychol 85:989-1005

Maher BA (1974) Delusional thinking and perceptual disorder. J Individ Psychol 30:98-113

Malhotra AK, Pinals DA, Weingartner H, Sirocco K, Missar CD, Pickar D, Breier A (1996) NMDA receptor function and human cognition: the effects of ketamine in healthy volunteers. Neuropsychopharmacology 14:301-307

Malhotra AK, Pinals DA, Adler CM, Elman I, Clifton A, Pickar D, Breier A (1997) Ketamine-induced exacerbation of psychotic symptoms and cognitive impairment in neuroleptic-free schizophrenics. Neuropsychopharmacology 17:141-150

Marek GJ, Wright RA, Schoepp DD, Monn JA, Aghajanian GK (2000) Physiological antagonism between 5-hydroxytryptamine (2A) and group II metabotropic glutamate receptors in prefrontal cortex. J Pharmacol Exp Ther 292:76-87

Margo A, Hemsley DR, Slade PD (1981) The effects of varying auditory input on schizophrenic hallucinations. Br J Psychiatry 139:122-127

Marr D (1982) Vision: a computational approach. Freeman, San Francisco

Matsuda LA, Lolait SJ, Brownstein MJ, Young AC, Bonner TI (1990) Structure of a cannabinoid receptor and functional expression of the cloned cDNA. Nature 346:561-564

McCormick DA, Wang Z, Huguenard J (1993) Neurotransmitter control of neocortical neuronal activity and excitability. Cereb Cortex 3:387-398

McCreery C, Claridge G (1996) A study of hallucination in normal subjects I: Self report data. Pers Indiv Differ 21:739-747

McGhie A, Chapman J (1961) Disorders of attention and perception in early schizophrenia. Br J Med Psychol 34:103-116

Mesulam MM (1998) From sensation to cognition. Brain 121(Pt 6):1013-1052

Milad MR, Wright CI, Orr SP, Pitman RK, Quirk GJ, Rauch SL (2007) Recall of fear extinction in humans activates the ventromedial prefrontal cortex and hippocampus in concert. Biol Psychiatry 62:446-454

Miller R (1976) Schizophrenic psychology, associative learning and the role of forebrain dopamine. Med Hypotheses 2:203-211

Miller EK, Cohen JD (2001) An integrative theory of prefrontal cortex function. Annu Rev Neurosci 24:167-202

Mishara A (2008) Autoscopy (the illusion of Seeing/Experiencing a Double): Disrupted Self in Neuropsychiatric Disorders and Anomalous Conscious States. In: Gallagher S, Schmicking D (eds) Handbook of phenomenology and cognitive science. Springer, Berlin

Moghaddam B, Adams BW (1998) Reversal of phencyclidine effects by a group II metabotropic glutamate receptor agonist in rats. Science 281:1349-1352

Moghaddam B, Adams B, Verma A, Daly D (1997) Activation of glutamatergic neurotransmission by ketamine: a novel step in the pathway from NMDA receptor blockade to dopaminergic and cognitive disruptions associated with the prefrontal cortex. J Neurosci 17:2921-2927 
Moreau JJ (1845/1973) Du Haschisch et l'alienation mentale. Raven, New York

Mumford D (1992) On the computational architecture of the neocortex. II. The role of cortico-cortical loops. Biol Cybern 66:241-251

Nelson CL, Burk JA, Bruno JP, Sarter M (2002) Effects of acute and repeated systemic administration of ketamine on prefrontal acetylcholine release and sustained attention performance in rats. Psychopharmacology (Berl) 161:168-179

Newcomer JW, Farber NB, Jevtovic-Todorovic V, Selke G, Melson AK, Hershey T, Craft S, Olney JW (1999) Ketamine-induced NMDA receptor hypofunction as a model of memory impairment and psychosis. Neuropsychopharmacology 20:106-118

O'Donnell P, Grace AA (1995) Synaptic interactions among excitatory afferents to nucleus accumbens neurons: hippocampal gating of prefrontal cortical input. J Neurosci 15:3622-3639

Oken BS (2008) Placebo effects: clinical aspects and neurobiology. Brain 131:2812-2823

Osmond H (1957) A review of the clinical effects of psychotomimetic agents. Ann N Y Acad Sci 66:418-434

Oye I, Paulsen O, Maurset A (1992) Effects of ketamine on sensory perception: evidence for a role of N-methyl-D-aspartate receptors. J Pharmacol Exp Ther 260:1209-1213

Pally R (2005) Non-conscious prediction and a role for consciousness in correcting prediction errors. Cortex 41:643-662 discussion $731-4$

Pally R (2007) The predicting brain: unconscious repetition, conscious reflection and therapeutic change. Int J Psychoanal 88:861881

Parthasarathi UD, Harrower T, Tempest M, Hodges JR, Walsh C, McKenna PJ, Fletcher PC (2006) Psychiatric presentation of voltage-gated potassium channel antibody-associated encephalopathy. Case report. Br J Psychiatry 189:182-183

Passie T, Karst M, Borsutzky M, Wiese B, Emrich HM, Schneider U (2003) Effects of different subanaesthetic doses of (S)-ketamine on psychopathology and binocular depth inversion in man. $\mathrm{J}$ Psychopharmacol 17:51-56

Patil ST, Zhang L, Martenyi F, Lowe SL, Jackson KA, Andreev BV, Avedisova AS, Bardenstein LM, Gurovich IY, Morozova MA, Mosolov SN, Neznanov NG, Reznik AM, Smulevich AB, Tochilov VA, Johnson BG, Monn JA, Schoepp DD (2007) Activation of mGlu2/3 receptors as a new approach to treat schizophrenia: a randomized Phase 2 clinical trial. Nat Med 13:1102-1107

Pavlov IP (1928) Lectures on conditioned reflexes. Lawrence \& Wishart, London

Pearce JM, Hall G (1980) A model for Pavlovian learning: variations in the effectiveness of conditioned but not of unconditioned stimuli. Psychol Rev 87:532-552

Pistis M, Ferraro L, Pira L, Flore G, Tanganelli S, Gessa GL, Devoto P (2002) Delta(9)-tetrahydrocannabinol decreases extracellular GABA and increases extracellular glutamate and dopamine levels in the rat prefrontal cortex: an in vivo microdialysis study. Brain Res 948:155-158

Pomarol-Clotet E, Honey GD, Murray GK, Corlett PR, Absalom AR, Lee M, McKenna PJ, Bullmore ET, Fletcher PC (2006) Psychological effects of ketamine in healthy volunteers. Phenomenological study. Br J Psychiatry 189:173-179

Rasmussen K, Aghajanian GK (1986) Effect of hallucinogens on spontaneous and sensory-evoked locus coeruleus unit activity in the rat: reversal by selective 5-HT2 antagonists. Brain Res 385:395-400

Rescorla RA, Wagner AR (1972) A theory of Pavlovian conditioning: variations in the effectiveness of reinforcement and nonreinforcement. In: Black $\mathrm{AH}$, Prokasy WF (eds) Classical conditioning II: current research and theory. Appleton-CenturyCrofts, New York
Rinaldi-Carmona M, Barth F, Heaulme M, Shire D, Calandra B, Congy C, Martinez S, Maruani J, Neliat G, Caput D et al (1994) SR141716A, a potent and selective antagonist of the brain cannabinoid receptor. FEBS Lett 350:240-244

Robbins TW, Everitt BJ (2007) A role for mesencephalic dopamine in activation: commentary on Berridge (2006). Psychopharmacology (Berl) 191:433-437

Rosenzweig N (1959) Sensory deprivation and schizophrenia: some clinical and theoretical similarities. Am J Psychiatry 116:326329

Rosenzweig N, Gardner L (1966) The role of input relevance in sensory isolation. Am J Psychiatry 122:920-928

Sarter M, Nelson CL, Bruno JP (2005) Cortical cholinergic transmission and cortical information processing in schizophrenia. Schizophr Bull 31:117-138

Sarter M, Martinez V, Kozak R (2008) A neurocognitive animal model dissociating between acute illness and remission periods of schizophrenia. Psychopharmacology (Berl) 202:237-258

Salama AA (1981) The autoscopic phenomenon: case report and review of literature. Can J Psychiatry 26:475-476

Schneider U, Leweke FM, Sternemann U, Weber MM, Emrich HM (1996) Visual 3D illusion: a systems-theoretical approach to psychosis. Eur Arch Psychiatry Clin Neurosci 246:256-260

Schultz W (1998) Predictive reward signal of dopamine neurons. J Neurophysiol 80:1-27

Schultz W, Dickinson A (2000) Neuronal coding of prediction errors. Annu Rev Neurosci 23:473-500

Scott DJ, Stohler CS, Egnatuk CM, Wang H, Koeppe RA, Zubieta JK (2007) Individual differences in reward responding explain placebo-induced expectations and effects. Neuron 55:325-336

Semple DM, Ramsden F, McIntosh AM (2003) Reduced binocular depth inversion in regular cannabis users. Pharmacol Biochem Behav 75:789-793

Shaner A (1999) Delusions, superstitious conditioning and chaotic dopamine neurodynamics. Med Hypotheses 52:119-123

Shanks DR (2006) Bayesian associative learning. Trends Cogn Sci 10: $477-478$

Sherman SM, Guillery RW (1998) On the actions that one nerve cell can have on another: distinguishing "drivers" from "modulators". Proc Natl Acad Sci U S A 95:7121-7126

Shi WX, Zhang XX (2003) Dendritic glutamate-induced bursting in the prefrontal cortex: further characterization and effects of phencyclidine. J Pharmacol Exp Ther 305:680-687

Skinner BF (1948) "Superstition" in the pigeon. J Exp Psychol 38:168-172

Smith GS, Schloesser R, Brodie JD, Dewey SL, Logan J, Vitkun SA, Simkowitz P, Hurley A, Cooper T, Volkow ND, Cancro R (1998) Glutamate modulation of dopamine measured in vivo with positron emission tomography (PET) and 11C-raclopride in normal human subjects. Neuropsychopharmacology 18:18-25

Sotty F, Damgaard T, Montezinho LP, Mork A, Olsen CK, Bundgaard C, Husum H (2009) Antipsychotic-like effect of retigabine [N-(2Amino-4-(fluorobenzylamino)-phenyl) carbamic acid ester], a KCNQ potassium channel opener, via modulation of mesolimbic dopaminergic neurotransmission. J Pharmacol Exp Ther 328:951-962

Spitzer M (1995) A neurocomputational approach to delusions. Compr Psychiatry 36:83-105

Spitzer M, Walter H (2003) The cognitive neuroscience of agency in schizophrenia. In: David A, Kircher T (eds) The self in neuroscience and psychiatry. Cambridge University Press, Cambridge, pp 436444

Stella N, Schweitzer P, Piomelli D (1997) A second endogenous cannabinoid that modulates long-term potentiation. Nature 388:773-778

Sterzer P, Frith C, Petrovic P (2008) Believing is seeing: expectations alter visual awareness. Curr Biol 18:R697-R698 
Stone JM, Pilowsky LS (2006) Psychopathological consequences of ketamine. Br J Psychiatry 189:565-566

Stone JM, Erlandsson K, Arstad E, Squassante L, Teneggi V, Bressan RA, Krystal JH, Ell PJ, Pilowsky LS (2008) Relationship between ketamine-induced psychotic symptoms and NMDA receptor occupancy: a [(123) I]CNS-1261 SPET study. Psychopharmacology (Berl) 197:401-408

Szabo ST, Machado-Vieira R, Yuan P, Wang Y, Wei Y, Falke C, Cirelli C, Tononi G, Manji HK, Du J (2009) Glutamate receptors as targets of protein kinase $\mathrm{C}$ in the pathophysiology and treatment of animal models of mania. Neuropharmacology $56: 47-55$

Turner DC, Aitken MR, Shanks DR, Sahakian BJ, Robbins TW, Schwarzbauer C, Fletcher PC (2004) The role of the lateral frontal cortex in causal associative learning: exploring preventative and super-learning. Cereb Cortex 14:872-880

Tyler DB (1955) Psychological changes during experimental sleep deprivation. Dis Nerv Syst 16:293-299

van Berckel BN, Kegeles LS, Waterhouse R, Guo N, Hwang DR, Huang Y, Narendran R, Van Heertum R, Laruelle M (2006) Modulation of amphetamine-induced dopamine release by group II metabotropic glutamate receptor agonist LY354740 in nonhuman primates studied with positron emission tomography. Neuropsychopharmacology 31:967-977

Van Keuren-Jensen K, Cline HT (2006) Visual experience regulates metabotropic glutamate receptor-mediated plasticity of AMPA receptor synaptic transmission by homerla induction. J Neurosci 26:7575-7580

Volkow ND, Tomasi D, Wang GJ, Telang F, Fowler JS, Wang RL, Logan J, Wong C, Jayne M, Swanson JM (2009) Hyperstimulation of striatal D2 receptors with sleep deprivation: Implications for cognitive impairment. Neuroimage 45:1232-1240

Vollenweider FX, Leenders KL, Oye I, Hell D, Angst J (1997a) Differential psychopathology and patterns of cerebral glucose utilisation produced by (S)- and (R)-ketamine in healthy volunteers using positron emission tomography (PET). Eur Neuropsychopharmacol 7:25-38

Vollenweider FX, Leenders KL, Scharfetter C, Antonini A, Maguire P, Missimer J, Angst J (1997b) Metabolic hyperfrontality and psychopathology in the ketamine model of psychosis using positron emission tomography (PET) and [18F]fluorodeoxyglucose (FDG). Eur Neuropsychopharmacol 7:9-24

Vollenweider FX, Vontobel P, Oye I, Hell D, Leenders KL (2000) Effects of (S)-ketamine on striatal dopamine: a [11C]raclopride PET study of a model psychosis in humans. J Psychiatr Res 34:35-43

Waelti P, Dickinson A, Schultz W (2001) Dopamine responses comply with basic assumptions of formal learning theory. Nature 412:43-48

Waltz JA, Frank MJ, Robinson BM, Gold JM (2007) Selective reinforcement learning deficits in schizophrenia support predictions from computational models of striatal-cortical dysfunction. Biol Psychiatry 62:756-764

Whitson JA, Galinsky AD (2008) Lacking control increases illusory pattern perception. Science 322:115-117

Williamson S, Gossop M, Powis B, Griffiths P, Fountain J, Strang J (1997) Adverse effects of stimulant drugs in a community sample of drug users. Drug Alcohol Depend 44:87-94

Worden W (1954) General Dean's story. Weidenfield and Nicholson, London

Yashiro K, Corlew R, Philpot BD (2005) Visual deprivation modifies both presynaptic glutamate release and the composition of perisynaptic/ extrasynaptic NMDA receptors in adult visual cortex. J Neurosci 25:11684-11692

Young BG (1974) A phenomenological comparison of LSD and schizophrenic states. Br J Psychiatry 124:64-74

Young G (2008) Capgras delusion: an interactionist model. Conscious Cogn 17:863-876

Yu AJ, Dayan P (2002) Acetylcholine in cortical inference. Neural Netw 15:719-730

Yu AJ, Dayan P (2005) Uncertainty, neuromodulation, and attention. Neuron 46:681-692 